\title{
FUNDOSCOPIC FINDINGS IN PATIENTS PRESENTING WITH PRIMARY HEADACHE DISORDERS.
}

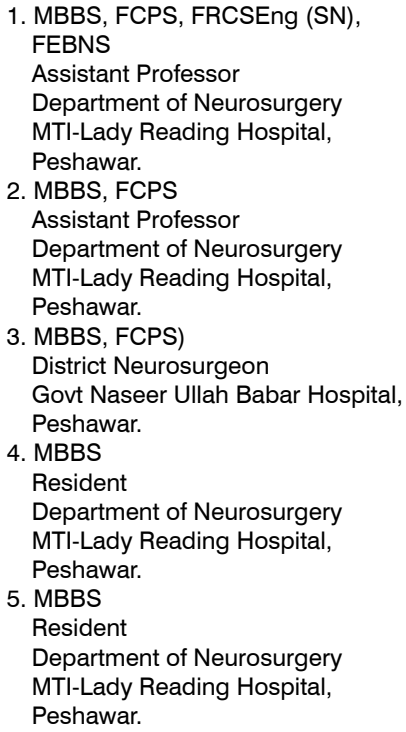

Correspondence Address: Dr. Bilal Khan

Street K, Arbab Sabzali Town, Warsak Road, Peshawar. bkafridi675@yahoo.com

Article received on:

22/06/2018

Accepted for publication:

09/03/2019

Received after proof reading: 30/09/2019

\section{INTRODUCTION}

Primary headache is a common symptom in the general population. It is the most common neurological symptoms, more than $50 \%$ of the population complains of headache in a year, and more than $90 \%$ of the general population report headache in a life time. ${ }^{1,2}$ The causes of primary headache range from many to as simple as tension headache, migraine and cluster headache, and overall these disorders account for approximately $95 \%$ of all headache complaints. ${ }^{3}$ The causes of secondary headaches are having a more sinister pathology like brain lesion, hydrocephalus following trauma, infection in the paranasal sinus. ${ }^{4}$ Headache due to secondary causes, especially

\begin{abstract}
Bilal Khan', Khalid Khanzada', Muhammad Usman Khan ${ }^{3}$, Sajjad Ullah", Usman Haqqani ${ }^{5}$ Babar Memorial Hospital, Kohat Road, Peshawar. Period: December 2016 to December 2017. ane on whom a fundoscopy was done, were included in the study. The age, gender, were noted on a proforma. Any positive findings on fundos evaluated by an ophthalmologist under the slit lamp. All patients with history of recent trauma, focal neurological deficit, and those who had undergone brain imaging were excluded from the study. Consent was taken from all the patients. The data was analyzed by SPSS version 19, and was expressed in the form of tables and charts. Results: A total of 19,000 patients were evaluated in the Neuro-OPD during study period, and 1086 patients were having headache. Majority of the patients were females with a number of 619 (56.99\%), while $447(43.01 \%)$ were males. The male to female ratio was approaching 1.38:1. Age range was from 9 to 62 years and the mean age was 37 years. Duration of symptoms was from 20 days to 12 years with a ing pappiledema, diabetic and hypertensive changes. Subsequent Brain imaging was done in $93(8.5 \%)$ patients, majority of them were on patients' request, and only 7 patients were having an intracranial lesion. Conclusion: A minority of patients with headache without any and should be performed in every patient with headache.
\end{abstract}

Fundoscopy, Imaging, Neurosurgery, Out Patient Department (OPD), Primary Headache, Pappiledema. findingsin patients presenting with primary headache disorders. Professional Med J 2019; 26(10):1765-1769. DOI: 10.29309/TPMJ/2019.26.10.4138 
disc margin, called in pappiledema. However, there can be other causes of pappiledema, like hydrocephalus. Also, many patients with hypertension and diabetes have retinal abnormalities, and may present with headache, fundoscopy gives an insight into these diseases and their progress, with a clue to the headache. ${ }^{6}$

Since Neurosurgeons receive a lot of patients with headache, and most of them are construed as simple tension headache, and patients also perceive it as a trivial symptom-a result of social problems, this simple test of performing a fundoscopic examination may reveal any underlying pathology, and such patients could be further evaluated with imaging studies to confirm/ exclude any underlying pathology. This was the bases of our study, as we wanted to know how many patients with simple headaches have abnormal/findings on imaging and fundoscopy.

\section{MATERIALS AND METHODS}

This study was conducted in the Neurosurgery unit of Govt. Naseer Ullah Babar Memorial Hospital, Kohat Road, Peshawar from December 2016 to December 2017. All patients presenting to the Neurosurgical OPD with complaints of headache, without any added neurology, who had undergone a fundoscopy were included in the study. The name, age, gender, duration of symptoms, findings on the fundoscopy, and the need for further studies i.e. CT brain were noted on a proforma. Any positive findings on fundoscopy were further evaluated by an ophthalmologist under the slit lamp, and if needed were also evaluated by a head CT, to rule out any lesion, though some patients with chronic headaches insisted for brian imaging. Patients with history of recent trauma, focal neurological deficit, and those who had undergone brain imaging were excluded from the study. Consent was taken from all the patients. The data was analyzed by SPSS version 19, and was expressed in the form of tables and charts.

\section{RESULTS}

A total of 19,000 patients were evaluated in the Neuro-OPD during study period, and 1086 $(5.71 \%)$ patients were having complaints of headache.

Majority of the patients were females with a number of $619(56.99 \%)$, while $447(43.01 \%)$ were male, the male to female ratio was approaching 1.38:1. Age range was from 9 to 62 years and the mean age was 37 years. Duration of symptoms was from 20 days to 12 years with a mean duration of 9 months.

Positive findings were noted in a minority of patients $2.5 \%(\mathrm{n}=28)$ including pappiledema, diabetic and hypertensive changes. Subsequent Brain imaging was done in $93(8.5 \%)$ patients, most of them were on patients' request, and only 7 patients were having an intracranial lesion in the form of brain tumor like pituitary lesion, large glioma and meningioma.

Neuro OPD

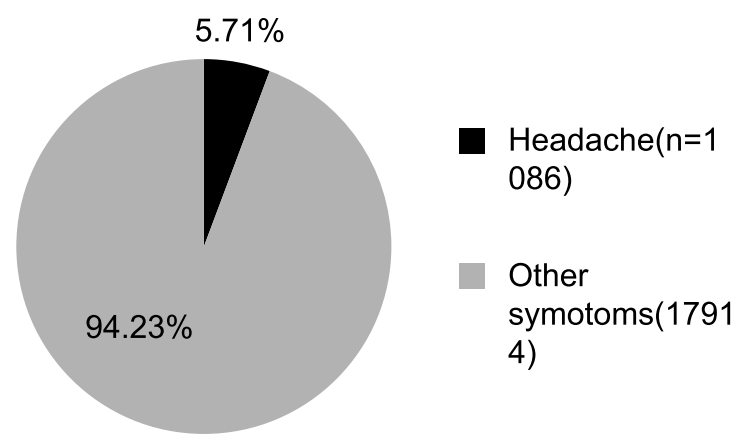

Figure-1. Shows the percent of patients presenting to the neurosurgical OPD with chief complaints of headache.

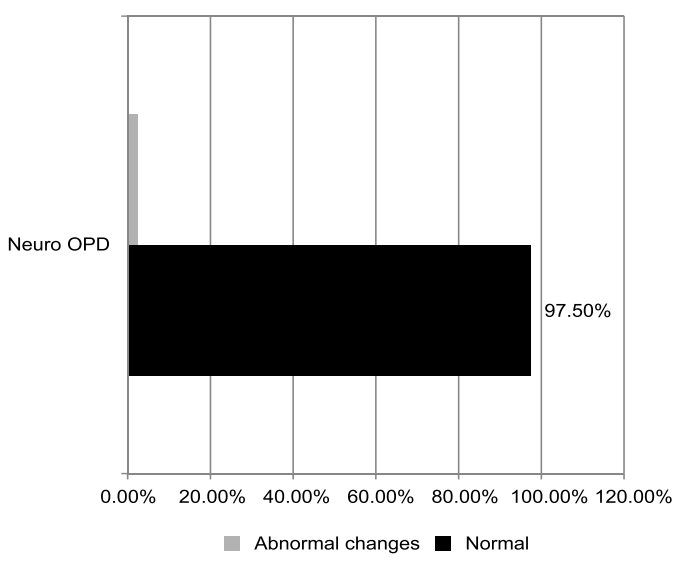

Figure-2. Shows the proportion of patients with abnormal fundoscopic findings in patients with headaches. 


\section{DISCUSSION}

Fundoscopy is an important examination and gives us an overview into the central nervous system (CNS) pathologies, presenting as visual problems. It is simple and quick and can be performed in the outpatient department of any neurosurgical, general medicine, or ophthalmology clinic. Headache is one of the common symptoms of patients presenting to the Neurosurgical OPD, and to diagnose any underlying intracranial pathology is of utmost importance. Since fundoscopy is the only available option for examining these patients in the OPD, therefore we did fundoscopic examination in all patients presenting with headache.

In our study $5.71 \%$ of the total patients presenting to the neuro-OPD were complaining of headache. In a study by Chaudary et $\mathrm{al}^{7}$ showed that $16 \%$ of the patients presenting to the neuro opd were having complaints of headache, and is reported about as high as $31.6 \%$ by Tegueu CK et al. ${ }^{8}$ But as reported by Bhandri $\mathrm{R}$ et $\mathrm{al}^{9}$, only $1 \%$ of the patients were having symptoms of the headache, presented to the General practice OPD. Our unit is a secondary level hospital, without having inpatient facility of the CT brain-that is why much of our patients' bulk, with complaints of headache is lower than a usual neurology or neurosurgery OPD. Furthermore, since we seldom operate on patients for brain surgery (tumor) in our unit, and the unit has been famous for the spine surgery, that's why the bulk of patient seeking advice for headache or brain related disorder is quite low.

Females more often presented (56.99\%) with the complaints of headache than males in a ratio of 1.38:1. Females outnumber males by a ratio of $1.2-2$, and this has been reported from studies both from Africa ${ }^{10,11}$ and Western countries. ${ }^{1,2,21}$ In a study by Lipton RB et $\mathrm{al}^{12}$, NAP showed that 28 million female suffer from migraine headache, compare to 7 million males. The high prevalence of headache among the females population is attributed to the sensitivity to estrogen receptor, genetics, and differences in response to pain and stresses. ${ }^{13}$ The mean age of patients presenting with headache in our study was 37 years though, it ranged from 9 to 63 years. The pediatric population-accompanied by their parents were mostly having problems at school; while the middle aged females had mostly underlying domestic problems. The most common age group has been a middle age group, as also reported by Lipton $\mathrm{RB}$ et al. ${ }^{12}$

The patients had duration of symptoms ranging from 20 days to 12 years. Most of them have taken medications for this purpose, and had consulted many physicians before consulting us in the OPD. Headache is a lasting and highly prevalent symptom in the society- Rassmussen $\mathrm{BK}^{4}$ report that the prevalence of headache was almost $93 \%$ in a population based study, Gobel $\mathrm{H}^{14}$ reported the prevalence of headache in Germany was $71.4 \%$, while Peng KP et $\mathrm{al}^{15}$ report shows that the prevalence of headache in the Asia Pacific region shows $27 \%$. The most common type of primary headache was Tension type headache (TTH), Migraine, and Chronic Daily Headache $(\mathrm{CDH}) \cdot{ }^{1,2,14,21}$

Positive fundoscopic findings in patients with headache was found only in 28 patients (2.5\%). These included pappiledema, hypertensive and diabetic changes. The patients were further evaluated by an ophthalmologist, for confirmation. Chatziali IP ${ }^{16}$, published his results on the fundoscopic findings in patients with headache referred by an ophthlmologist, which included pappiledma in $2.4 \%$ of patients. Thulasi $\mathrm{P}^{17}$ reported a ocular fundus abnormalities were present in as high as $8.5 \%$, however, it was done in an emergency setting, and the patients presented with severe headaches, while in our case it was in outpatient clinic and the patients were in a good state of health, otherwise.

Brain imaging was done in $93(8.5 \%)$, and the majority of them was on the patient's own request, because they were worried about any underlying cause, especially tumor or vessel which they called rugg, in their local language meaning vessel. Majority of them were also worried about the possibility of a stroke-as they have heard from other people about headache and association of stroke. The usual indication for brain imaging in patients with headache is the presence of any 
neurological signs/symptoms, seizures, and/or pappiledema. Since as per our selection criteria for the headache, all of the patients having such neurological signs were excluded from the study, and the patients with positive fundoscopic findings were very few; and, as stated all of them had these imaging done on request. Forsyth $\mathrm{PA}^{18}$ reported that all patients with new onset severe headache, patients with changing pattern of long standing or recurrent headache including nausea/vomiting and associated neurological findings should have a brain imaging done in the form of CT or MRI. From a neurosurgical point of view the most important finding on the fundoscopic examination is pappiledema, which was positive only in a minority of patients, and subsequent brain imaging revealed an intracranial pathology like glioma, meningioma and pituitary adenoma. Around $30 \%$ of brain tumors present as pappiledema ${ }^{19}$, and Intracranial lesion in the population with a headache without any added neurology is very uncommon, and has been reported in a large review of 3026 scans of patients with headache showed that only a minority of patients suffered from a serious disease that could be diagnosed with cerebral imaging these included $0.8 \%$ brain tumours; $0.2 \%$ arteriovenous malformations, $0.3 \%$ hydrocephalus, $0.1 \%$ aneurysm, $0.2 \%$ subdural haematoma, $1.2 \%$ strokes- including chronic ischaemic processes, as reported by Evans. ${ }^{20}$ Chaterzelli $^{16}$ reported that $4.6 \%$ of patients with headache were having Intracranial pathologies, and whereas Ramirez $\mathrm{LM}^{21}$ reported it in patients seeking emergency care due to headache; those with the increased risk are with occipitonuchal location, age greater than 55 years, and associated neurological findings. Since fundoscopy is the only examination which can give insight into the brain pathology and it does not costs any additional charges to the patient, it is the best tool to evaluate patients with headache, and all patients complaining of headache should undergo fundoscopy-to rule out pathology that requires further evaluation/ treatment.

\section{CONCLUSION}

A minority of patients with primary headache disorder had abnormal findings on examination of fundi, and further follow up/imaging revealed the underlying cause. So, the importance of fundoscopy cannot be overruled, and should be performed in every patient with headache-as it may be the only symptom of the underlying pathology.

Copyright(C) 09 March, 2019.

\section{REFERENCES}

1. Manzoni GC, Stovner LJ. Epidemiology of headache. Handb Clin Neurol 2010; 97:3-22.

2. Stovner L, Hagen K, Jensen R, Katsarava Z, Lipton $R$, Scher $A$ et al. The global burden of headache: A documentation of headache prevalence and disability worldwide. Cephalalgia 2010; 27:193-210.

3. Brust JCM. Lange current diagnosis \& treatment neurology. New York, NY: McGraw-Hill 2007.

4. Rasmussen B, Jensen Schroll M, Olesen J. Epidemiology of headache in a general population A prevalence study. Journal of Clinical Epidemiology. 1991; 44(11):1147-57.

5. Greenberg MS. Handbook of neurosurgery, Theime publications, NY, 2016, 110-121.

6. Gunderson GA, Karnath B. Retinal manifestations of diabetes mellitus and hypertension. In: Hospital Physician Nov 2003; 39(11):15-8.

7. Chowdhury AH, ghose SK, Ahmed KGU, et al. Pattern of disorders in neurology outpatient department: Experience from a tertiary care hospital in Bangladesh. J Dhaka Med Coll. 2016; 25(1): 53-57.

8. Tegueu CK, Nguefack S, Doumbe J, et al. The spectrum of neurological disorders presenting at a neurology clinic in Yaoundé, Cameroon. Pan African Medical Journal. 2013; 14: 148. doi:10.11604/ pamj.2013.14.148.2330.

9. BhandariR, Bhandari R, Shakya DR, Maskey R, Paudel M, Giri M, Gupta PP. Chronic headache among general practice out patients in a Tertiary Care Hospital, Eastern Nepal. Health Renaissance 2015; 13(2): 22-29.

10. Onwuekwe IO, Ezeala-Adikaibe B, Ekenze OS: Neurological disease burden in two semi-urban communities in South East Nigeria. Nig J Med 2012, $1(3): 317-319$.

11. Takele GM, Haimanot RT, Martelleti P: Prevalence and burden of headache in Akaki Textile Mill Workers, Ethiopia. J Headache Pain 2008, 9(2):119-128. 
12. Lipton RB, Bigal ME, Diamond M, Freitag F, Reed ML, Stewart WF. Migraine prevalence, disease burden, and the need for preventive therapy. Neurology. 2007 Jan 30; 68(5):343-9.

13. Liverman CS, Brown JW, Sandhir R, Klein R, McCarson $\mathrm{K}$, Berman NEJ. Oestrogen increases nociception through ERK activation in the trigeminal ganglion: Evidence for a peripheral mechanism of allodynia. Cephalalgia 2009; 29 (5):520-31.

14. Göbel H, Braun MP, Soyka D. The epidemiology of headache in Germany: A nationwide survey of a representative sample on the basis of the headache classification of the international headache society. Cephalalgia 1994; 14(2): 97 - 106.

15. Peng KP, Wang SJ. Epidemiology of headache disorders in the Asia-pacific region. Headache. 2014 Apr; 54(4):610-8. doi: 10.1111/head.12328. Epub 2014 Mar 25.

16. Chatziralli IP, Kanonidou ED, Keryttopoulos P, Dimitriadis $P$, Papazisis LE. The value of fundoscopy in general practice. The Open Ophthalmology Journal. 2012; 6:45. doi:10.2174/1874364101206010004.
17. Thulasi P, Fraser CL, Biousse V, Wright DW, Newman NJ, Bruce BB. Nonmydriatic ocular fundus photography among headache patients in an emergency department. Neurology. 2013(29); 80(5):432-7. doi: 10.1212/WNL.0b013e31827f0f20. Epub 2013 Jan 2.

18. Forsyth PA, Posner JB. Headache in patients with brain tumors: A study of 111 patients. Neurology 1993; 43: 1678-83.

19. Serova N, Eliseeva N, Shifrin M. Papilloedema in Patients With Brain Tumour, Neuro-Ophthalmology 2009; 33:3, 100-5.

20. Evans R. Diagnostic testing for the evaluation of headaches. Neurol Clin 1996; 14: 1-26.

21. Ramirez LM, Espinosa CE, Cicero JJ et al. Predictors of intracranial pathologic findings in patients seek emergency care because of headache. Arch Neuro 1997; 54(12), 1506-9.

\begin{tabular}{|c|c|c|c|}
\hline \multicolumn{4}{|c|}{ AUTHORSHIP AND CONTRIBUTION DECLARATION } \\
\hline Sr. \# & Author-s Full Name & Contribution to the paper & Author's Signature \\
\hline 1 & Bilal Khan & $\begin{array}{l}\text { Conceive the idea, Literature } \\
\text { review. }\end{array}$ & \\
\hline 3 & Muhammad Usman Khan & $\begin{array}{l}\text { Literature review, Analysis of } \\
\text { data. }\end{array}$ & \\
\hline 4 & Sajjad Ullah & $\begin{array}{l}\text { Literature review and data } \\
\text { analysis. }\end{array}$ & \\
\hline 5 & Usman Haqqani & $\begin{array}{l}\text { Data preparation, Analysis } \\
\text { and literature review. }\end{array}$ & \\
\hline
\end{tabular}

